\begin{tabular}{|c|c|c|}
\hline \multirow{3}{*}{$\begin{array}{r}\text { Case Reports in } \\
\text { Gastroenterology }\end{array}$} & \multirow{2}{*}{\multicolumn{2}{|c|}{ Case Rep Gastroenterol 2016;10:344-351 }} \\
\hline & & \\
\hline & $\begin{array}{l}\text { DOI: } 10.1159 / 000447291 \\
\text { Published online: June 27, } 2016\end{array}$ & $\begin{array}{l}\text { (c) } 2016 \text { The Author(s) } \\
\text { Published by S. Karger AG, Basel } \\
\text { www.karger.com/crg }\end{array}$ \\
\hline & \multicolumn{2}{|c|}{$\begin{array}{l}\text { This article is licensed under the Creative Commons Attribution-NonCommercial } 4.0 \\
\text { International License (CC BY-NC) (http://www.karger.com/Services/OpenAccessLicense) } \\
\text { Usage and distribution for commercial purposes requires written permission. }\end{array}$} \\
\hline
\end{tabular}

\title{
A Giant Gastrointestinal Stromal Tumor of the Stomach with Extramural Growth
}

\author{
Ryosuke Miyazaki $^{\mathrm{a}}$ Seiji Arihiro ${ }^{\mathrm{a}}$ Eri Hayashi $^{\mathrm{a}}$ Takuya Kitahara $^{\mathrm{a}}$ \\ Sayumi Oki ${ }^{a}$ Syunsuke Kamba ${ }^{a}$ Daisuke Ide ${ }^{a} \quad$ Nobuhiko Komoike $^{a}$ \\ Kenichi Satoh $^{a}$ Masayuki Saruta $^{a}$ Tomohiro Kato $^{a}$ Hisao Tajiri ${ }^{b}$ \\ Hiroaki Aoki ${ }^{c}$ Nobuo Omura ${ }^{c}$ Norio Mitsumori ${ }^{c}$ Takehiro Mitsuishi ${ }^{d}$ \\ Haruka Yanagisawa $^{d}$ Hiroyuki Takahashi $^{d}$ \\ ${ }^{a}$ Division of Gastroenterology and Hepatology, Department of Internal Medicine, The Jikei \\ University School of Medicine, Minato-ku, Tokyo, Japan; ${ }^{b}$ Department of Innovative \\ Interventional Endoscopy Research, The Jikei University School of Medicine, Minato-ku, \\ Tokyo, Japan; 'Division of Gastrointestinal Surgery, The Jikei University School of \\ Medicine, Minato-ku, Tokyo, Japan; ${ }^{d}$ Department of Pathology, The Jikei University School \\ of Medicine, Minato-ku, Tokyo, Japan
}

\section{Keywords}

Gastrointestinal stromal tumor · Gastric submucosal tumor · Mesenchymal tumor

\begin{abstract}
A 76-year-old man presented to our hospital with abdominal distention and loss of appetite. The $10 \%$ of weight lost relative to this patient in 1 month. Abdominal computed tomography and magnetic resonance imaging revealed a giant mass, with a major axis of $23 \mathrm{~cm}$, containing solid components, not involving the upper abdominal organs. Esophagogastroduodenoscopy showed extramural compression from the middle gastric body to the antrum, as well as a normal mucosal surface. These findings were suggestive of a gastrointestinal stromal tumor attached to the anterior wall of the stomach without metastasis or invasion. Partial gastrectomy was performed for tumor resection, and the patient was subsequently treated with adjuvant imatinib. We report a rare case of a large extramural gastrointestinal stromal
\end{abstract}




\section{Case Reports in Gastroenterology}

Case Rep Gastroenterol 2016;10:344-351

10.1159/000447291

c 2016 The Author(s). Published by S. Karger AG, Basel www.karger.com/crg

Miyazaki et al.: A Giant Gastrointestinal Stromal Tumor of the Stomach with Extramura Growth

tumor of the stomach that was larger than $20 \mathrm{~cm}$ in diameter and present a pertinent literature review.

\section{Introduction}

Gastrointestinal stromal tumors (GISTs) are mesenchymal tumors that may develop anywhere within the gastrointestinal tract. The annual incidence of GISTs is 12.7 per million [1]. They are defined as CD117-(C-kit) or CD34-positive spindle cell tumors and are derived from interstitial cells of Cajal. The most common site of growth is the stomach, accounting for $60-70 \%$ of the entire gastrointestinal tract, followed by the small intestine, large intestine, and esophagus [2]. In the stomach, developmental morphology is classified as exogastric (30-40\%), intramural (29-44\%), endogastric (18-22\%), and mixed type (16-22\%) based on the Skandalakis classification for leiomyomas [3].

The GIST treatment guidelines show risk classifications combining tumor diameter and karyokinesis count, which is an index of cell proliferation potential. Tumors with a diameter of $\geq 5 \mathrm{~cm}$ and karyokinesis count of $\geq 5 / \mathrm{HPF}$ are classified into the high-risk group. Other factors that increase recurrence risk in malignant cases include hematogenous metastasis, invasion of surrounding tissue, peritoneal metastasis, and tumor rupture.

We treated a patient with a giant submucosal tumor of the stomach with extramural growth that was pathologically diagnosed as a classical GIST postoperatively. We hereby report our case and discuss a few previous reports.

\section{Case Report}

A 76-year-old man presented to our hospital with a feeling of abdominal fullness and poor appetite for approximately 1 month; he had lost $7 \mathrm{~kg}$, a $10 \%$ weight loss relative to his initial weight. Of note, he had a medical history of myocardial infarction. During a regular checkup at the cardiovascular medicine department at our hospital, a computed tomography (CT) scan of the abdominal region revealed a giant, solid mass occupying the epigastrium. He was introduced to our department. An irregular-shaped solid mass with elastic hardness, of the size of an infant's head, was palpated in the epigastrium. No pain or tenderness was noted. Blood test results after admission indicated mild normocytic and normochromic anemia (hemoglobin, $11.3 \mathrm{~g} / \mathrm{dl}$ ) and elevated inflammatory response (C-reactive protein, $10 \mathrm{mg} / \mathrm{dl}$; table 1). Contrast-enhanced abdominal CT revealed a giant, solid mass with a diameter of 23 $\mathrm{cm}$ occupying the epigastrium, and the gastric corpus was markedly displaced to the left. In the arterial phase, an aneurysm formed within the tumor and the contrast agent was pooling. The left gastric artery had also developed as the feeding vessel. Gallstones were detected; otherwise, no obvious metastatic lesions in other organs were seen. Abdominal contrast magnetic resonance imaging showed an irregularly shaped tumor with hypoechoic signals on T1 images, and mixed areas of high and low intensity were noted on T2 images in the epigastrium. The tumor had dominant borders, with a poorly enhanced area in the center, indicating internal necrosis. Much of the tumor was in contact with the liver, which was being excluded. However, it was clearly demarcated, with regular borders and no apparent invasion (fig. 1). Extramural growth from the posterior wall of the middle stomach to the pyloric region was seen during esophagogastroduodenoscopy (EGD). Passage from the stomach to the duodenum was possible. 
Based on these findings, the diagnosis of a giant gastric submucosal tumor with extramural growth was established. Despite blood transfusions, anemia progressed.

Surgical findings indicated that a tumor had developed from the lesser curvature side of the stomach. It adhered to the transverse mesocolon, liver, and gallbladder; however, no invasion and metastatic lesions were detected. Therefore, distal gastrectomy and Roux-en-Y reconstruction were performed. Cholecystectomy was also performed for the gallstones. Macroscopic findings of the resected specimen showed a giant tumor of $23 \times 20 \times 13 \mathrm{~cm}$ on the gastric serosal side. Most of the tumor was covered in a capsule, but the capsule had broken in some places and parenchyma was disintegrating. The removed mass was pale pink, solid, and clearly demarcated. Severe bleeding necrosis was observed (fig. 2).

Histopathological findings indicated that tumor cells were spindle shaped and oval nuclei exhibited tight, intricate hyperplasia in bundles below muscularis propria of the stomach. Karyokinesis count was 7-8/HPF (400 10 field mean value). On immunohistochemistry, the tumor cells were indicated to be CD117 (C-kit) $(+), \operatorname{CD} 34(+), \mathrm{S}-100(-), \alpha-\mathrm{SMA}(\alpha-$ smooth muscle actin)(-), and desmin(-) (fig. 3). The Ki67 positivity rate was approximately $40 \%$. No metastatic lesions were noted in the greater omentum. Thus, a diagnosis of classical GIST was made, and the tumor was classified into the high-risk group due to the high karyokinesis count and larger diameter.

Imatinib (300 mg/day) was initiated as adjuvant therapy on post-operative day 84 .

\section{Discussion}

We performed a literature search on the American Medical Abstracts Society for articles published from 2006 through 2015 using the keywords gastric GIST and giant and excluded meeting minutes. We found only 7 reports of lesions with a maximum diameter of $20 \mathrm{~cm}$ or greater over 10 years. Five of these (71\%) were in males and most patients (six patients, 86\%) were 50-60 years old. The most common complaint was a feeling of fullness in the abdominal region (four patients, 57\%), followed by abdominal pain (two patients, 29\%) (table 2) [4-10].

Because GIST of the stomach developed extramurally, there were few clinical symptoms until it grew large, and it was difficult to detect. When tumors become exceedingly large, they displace surrounding organs and it can be difficult to identify the primary onset site and perform differential diagnosis. Based on frequency, malignant tumors of the abdominal region requiring differentiation include GISTs, leiomyosarcomas, liposarcomas, desmoid tumors, and malignant fibrous histiocytomas. GISTs more than $4 \mathrm{~cm}$ often involve necrosis, which is observed as a non-contrasted area on enhanced CT, and we made similar observations in our case. In our case, CRP level was elevated up to $10 \mathrm{mg} / \mathrm{dl}$; however, it normalized after surgical resection. Thus, it appeared that necrosis in the GIST was causing the stimulated inflammatory response.

The utility of imaging modalities such as CT in definitive preoperative diagnosis of GISTs is limited. In many cases, tumor biopsy with endoscopic ultrasound-guided fine needle aspiration is performed. However, we did not perform this procedure on our patient in consideration of the risk of hemorrhage, as we had noted the formation of an aneurysm within the tumor. It has been reported that in GISTs of $10 \mathrm{~cm}$ or larger, the surface is nodular due to countless large vessels and the tissue weakens, making it prone to hemorrhage [11]. Therefore, in cases of giant tumors, eligibility for tumor biopsy for the purpose of preoperative diagnosis should be carefully considered taking into account the risk of hemorrhage and 
metastasis. There were no clinically malignant findings in our patient but the tumor was classified into the high-risk group based on the diameter and karyokinesis count.

The first choice for GIST treatment is complete surgical resection. Surgery should be performed taking into account the possibility of invasion of and adhesion to organs surrounding the tumor that cannot be identified on preoperative diagnostic imaging and the need for extended surgery. If a definitive diagnosis can be established based on histopathological findings, preoperative chemotherapy may also be considered as an option. Preoperative chemotherapy is performed to improve the complete resection rate, preserve organ function, and improve surgical safety [12]. However, it has also been reported that sudden reductions in tumor size may lead to adverse events such as tumor hemorrhage and tumor penetration. Postoperatively, it is recommended that adjuvant therapy with imatinib be administered for moderate and high-risk group tumors [13]. According to a recent placebocontrolled randomized trial, adjuvant therapy for initial-onset GISTs (C-KIT-positive, $3 \mathrm{~cm}$ or larger) involving $400 \mathrm{mg} /$ day of imatinib for one year was reported to be safe and suppress recurrence [13]. Thus, the recurrence-free survival rate was statistically significantly higher in the imatinib group. It has been reported that in the high-risk group, a postoperative recurrence rate of approximately $60 \%$ is observed but that adjuvant therapy is effective [14]. The recent randomized trial that comparatively investigated groups administered imatinib for 1 year and 3 years found that the recurrence-free survival period and overall survival period were better in the 3-year-administration group [15].

For our patient, we started imatinib postoperatively. As of 2 years after surgery, no recurrence has been observed. We will carefully monitoring in further follow-ups.

\section{Ethical Statement}

The authors have no ethical conflicts to disclose.

\section{Disclosure Statement}

All author report no conflict of interest related to his manuscript.

\section{References}

1 Goettsch WG, Bos SD, Breekvedt-Postma N, Casparie M, Herings RM, Hogendoorn PC: Incidence of gastrointestinal stromal tumours is underestimated: results of a nation-wide study. Eur J Cancer 2005;41:2868-2872.

2 Miettinen M, Lasota J: Gastrointestinal stromal tumors - definition, clinical, histological, immunohistochemical, and molecular genetic features and differential diagnosis. Virchows Arch 2001;438:1-12.

3 Skandalakis JE, Gray SW, Shepard D: Smooth muscle tumors of the stomach. Int Abstr Surg 1960;110:209-226.

4 Pamukcuoglu M, Budakoglu B, Han O, Tad M, Oksüzoğlu B, Abali H, Zengin N: An extraordinary case in whom gastrointestinal stromal tumor and low-grade malignant lymphoma are seen together in the stomach. Med Oncol 2007;24:351-353.

5 Funahashi H, Okada Y, Sawai H, et al: Complete extragastric growth in a giant gastrointestinal stromal tumor: report of a case. Int Surg 2008;93:45-49.

6 Cruz RJ Jr, Vincenzi R, Ketzer BM, Cecilio AL, Cepeda LA: Spontaneous intratumoral bleeding and rupture of giant gastric stromal tumor $(>30 \mathrm{~cm})$ in a young patient. World J Surg Oncol 2008;6:76. 
Miyazaki et al.: A Giant Gastrointestinal Stromal Tumor of the Stomach with Extramura Growth

7 Colović R, Micev M, Matić S, Colović N, Grubor N, Atkinson HD: Malignant stromal tumor of the stomach with giant cystic liver metastases prior to treatment with imatinib mesylate. Vojnosanit Pregl 2013;70:225-228.

8 Cappellani A, Piccolo G, Cardì F, Cavallaro A, Lo Menzo E, Cavallaro V, Zanghì A, Di Vita M, Berretta M: Giant gastrointestinal stromal tumor (GIST) of the stomach cause of high bowel obstruction: surgical management. World J Surg Oncol 2013;11:172.

9 Notani H, Kawamura T, Sato T, Hoshino A, Sato Y, Nakajima A. [A case of a gastrointestinal stromal tumor of the stomach with extramural growth (article in Japanese)]. Jpn J Cancer Chemother 2013;40:2179-2181.

10 Ionescu S, Barbu E, Ionescu C, Costache A, Bălăşoiu M: Giant gastrointestinal stromal tumor of the stomach. Rom J Morphol Embryol 2015;56:239-245.

11 Shiu MH, Farr GH, Papachristou DN, Hajdu SI: Myosarcomas of the stomach: natural history, prognostic factors and management. Cancer 1982;491:177-187.

12 Cappellani A, Piccolo G, Cardi F, et al: Giant gastrointestinal stromal tumor (GIST) of the stomach cause of high bowel obstruction: surgical management. World J Surg Oncol 2013;11:172.

13 Demetri GD, Von Mehren M, Blanke CD, et al: Efficacy and safety of imatinib mesylate in advanced gastrointestinal stromal tumors. N Engl J Med 2002;347:472-480.

14 Dematteo RP, Ballman KV, Antonesc CR, et al: Adjuvant imatinib mesylate after resection of localized, primary gastrointestinal stromal tumor: a randomized, double-blind, placebo-controlled trial. Lancet 2009;373:1097-1104.

15 Joensuu H, Eriksson M, Sundby Hall K, et al: One vs three years of adjuvant imatinib for operable gastrointestinal stromal tumor: a randomized trial. JAMA 2012;307:1265-1272. 

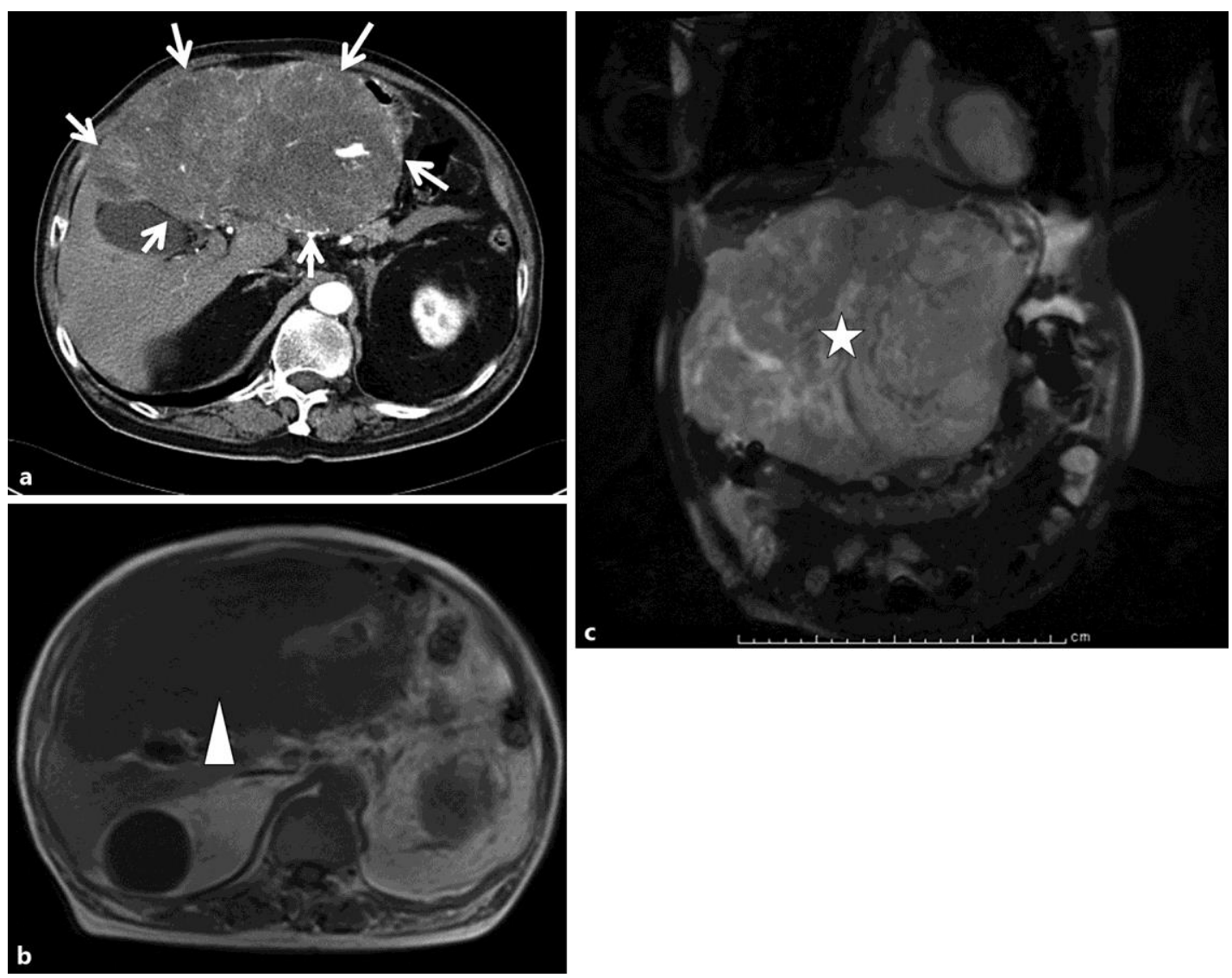

(C) 2016 The Author(s). Published by S. Karger AG, Basel www.karger.com/crg

Miyazaki et al.: A Giant Gastrointestinal Stromal Tumor of the Stomach with Extramura Growth

Fig. 1. Contrast-enhanced CT of the abdomen demonstrated a giant, solid mass with a diameter of $23 \mathrm{~cm}$, with homogeneous enhancement (arrows). In the arterial phase, formation of an aneurysm within the tumor was noted and the contrast medium was pooling (a). Contrast magnetic resonance imaging (MRI) of the abdominal region showed an irregularly-shaped tumor with hypoechoic signals (arrow head) on T1 images (b), and mixed hypoechoic and hyperechoic signals (asterisk) on T2 images (c) were noted in the epigastrium. 


\section{Case Reports in \\ Gastroenterology}

\begin{tabular}{l|l}
\hline Case Rep Gastroenterol 2016;10:344-351 \\
\hline $10.1159 / 000447291$ & $\begin{array}{l}\text { @ 2016 The Author(s). Published by S. Karger AG, Basel } \\
\text { www.karger.com/crg }\end{array}$ \\
\hline
\end{tabular}

Miyazaki et al.: A Giant Gastrointestinal Stromal Tumor of the Stomach with Extramural Growth
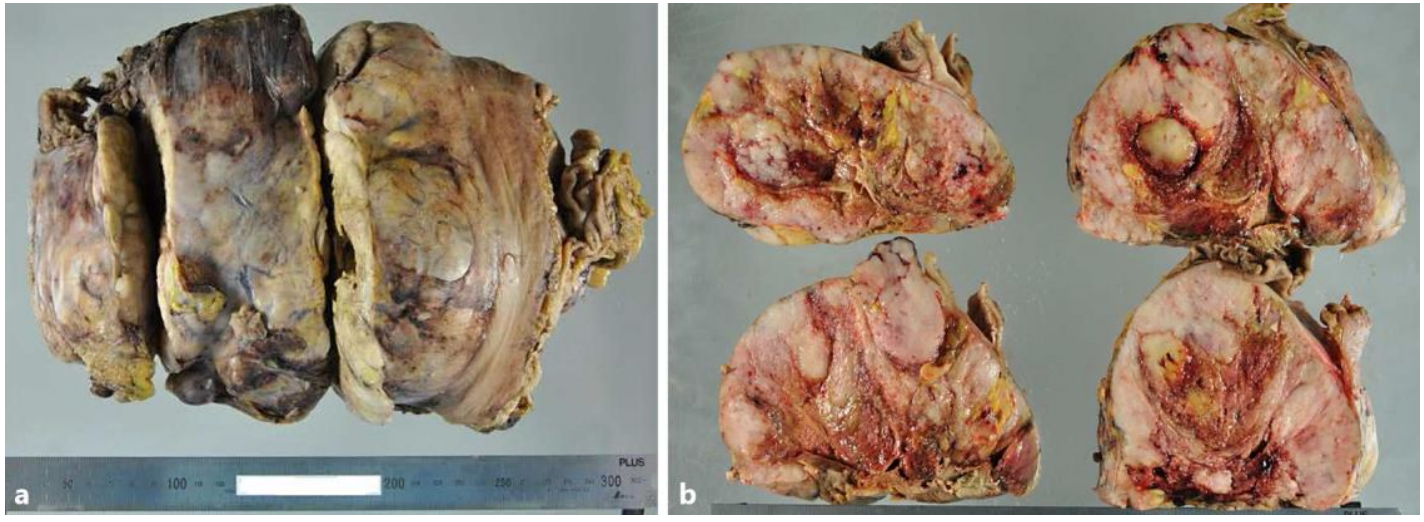

Fig. 2. Macroscopic findings of the resected specimen showed a giant tumor of $23 \times 20 \times 13 \mathrm{~cm}$ on the gastric serosa side. Most of the tumor was covered in a capsule but the capsule had broken in some places and parenchyma was disintegrating (a). The cut surface was clearly demarcated, pale pink, and solid. It was accompanied by severe bleeding necrosis (b).
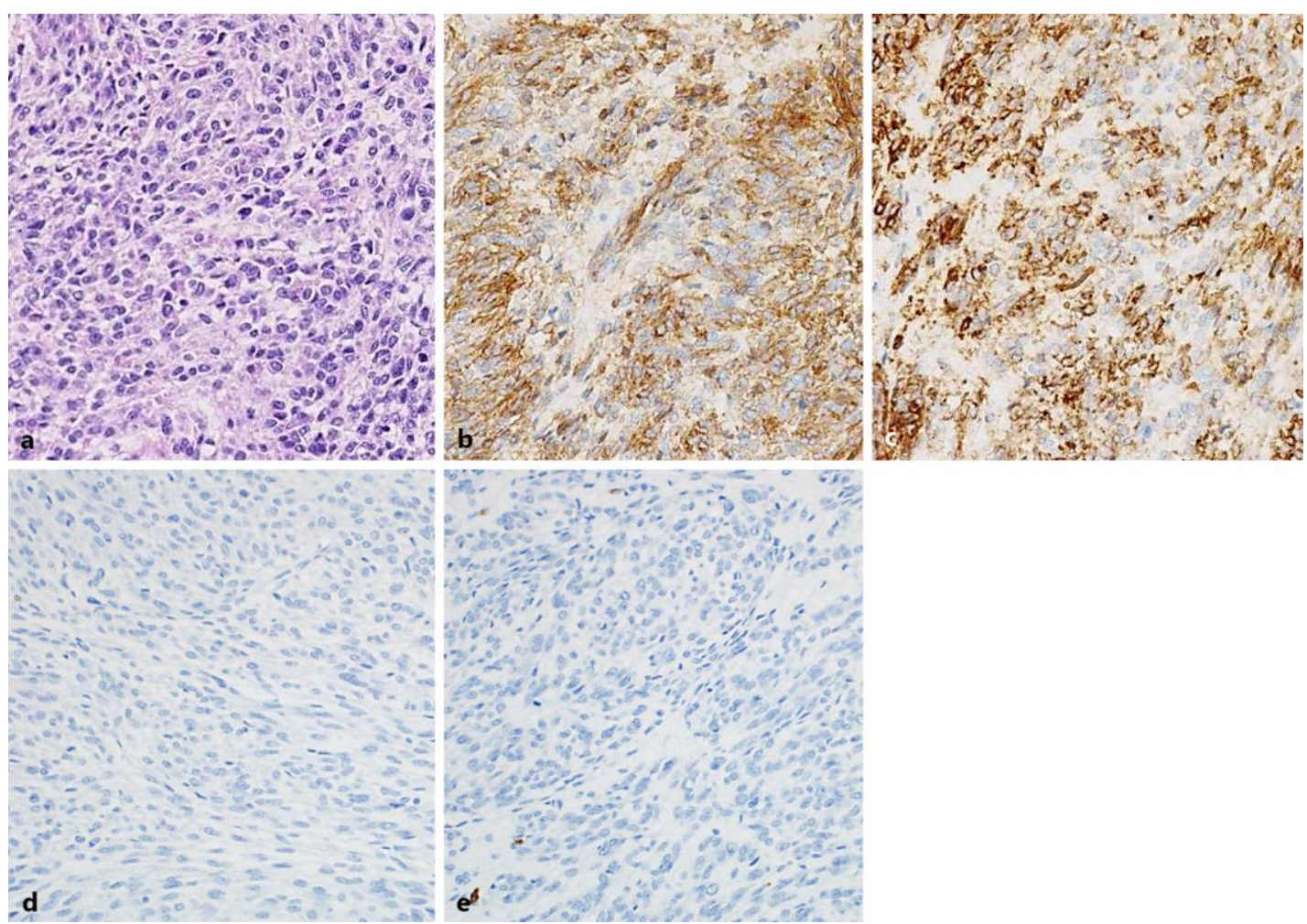

Fig. 3. Hematoxylin and eosin stained section indicated that cells with spindle-shaped and oval nuclei exhibited tight, intricate hyperplasia in bundles below the muscularis propria of the stomach (a). Immunohistochemistry results indicated that tumor cells were CD117 (C-kit) (+) (b) and CD34 (+) (c). Negative control staining for the immunohistochemistry were $S-100(-)$ (d) and $\alpha-\operatorname{SMA}(-)$ (e). 


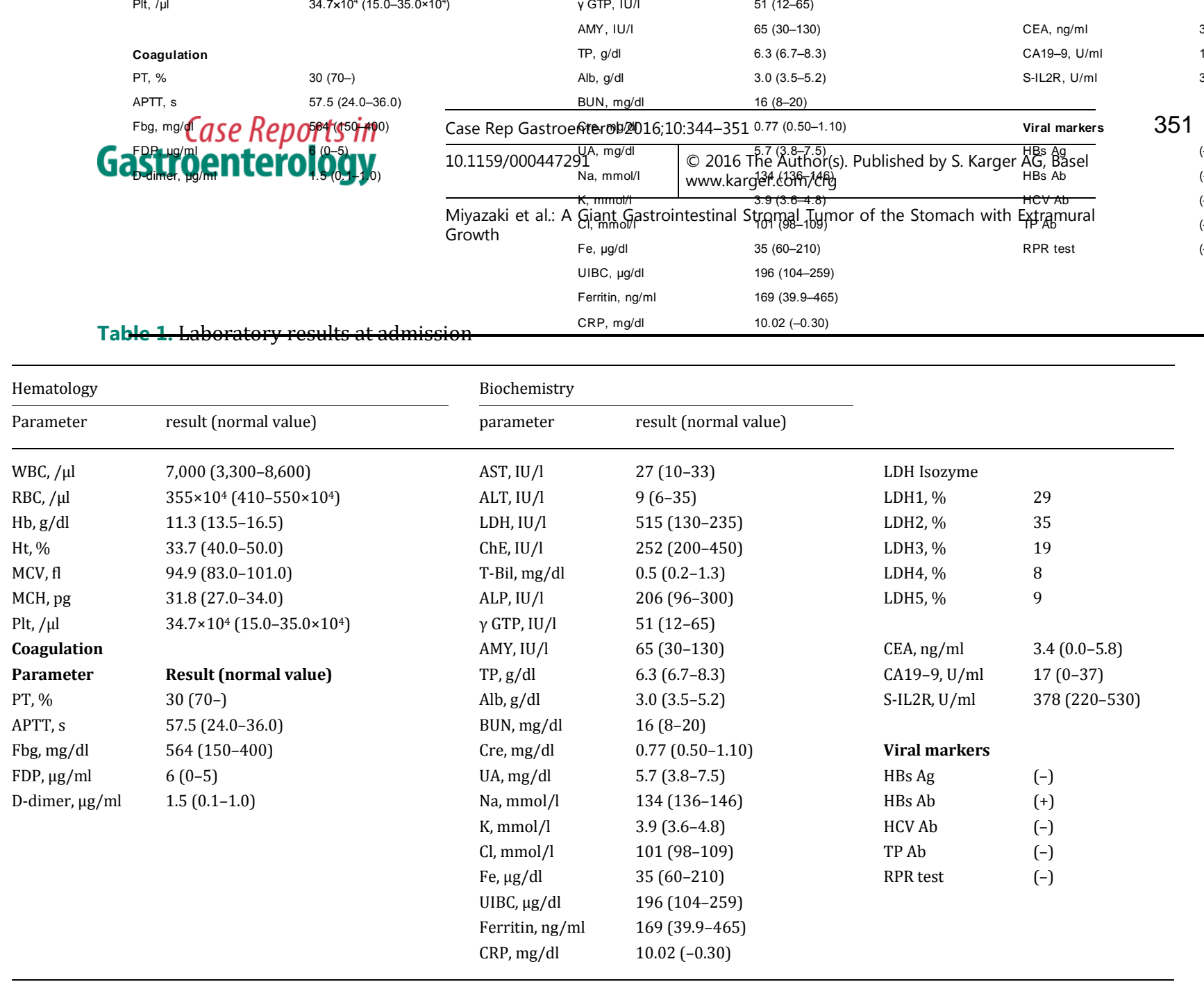

Table 2. Published reports of patients with a maximum diameter of $20 \mathrm{~cm}$ or greater between 2006 and 2015

\begin{tabular}{|c|c|c|c|c|c|c|c|c|c|}
\hline $\begin{array}{l}\text { Ca- } \\
\text { se }\end{array}$ & Year & Author & Age & Sex & Chief complaint & $\begin{array}{l}\text { Tumor size, } \\
\mathrm{cm}\end{array}$ & $\begin{array}{l}\text { Treat- } \\
\text { ment }\end{array}$ & Mitosis & Follow-up \\
\hline 1 & 2007 & Pamukcuoglu [9] & 68 & M & abdominal distension & $24 \times 16 \times 13$ & $\mathrm{~S}+\mathrm{CT}$ & $8-12 / 50 \mathrm{HPF}$ & 2 months \\
\hline 2 & 2008 & Funahashi [10] & 59 & M & diarrhea and anal bleeding & $18 \times 25 \times 11$ & $\mathrm{~S}$ & $12 / 10 \mathrm{HPF}$ & 6 years \\
\hline 3 & 2008 & Cruz Jr [11] & 37 & $\mathrm{M}$ & abdominal pain & $32 \times 25 \times 21$ & $\mathrm{~S}+\mathrm{CT}$ & 10/50HPF & 1 year \\
\hline 4 & 2013 & Colovic [12] & 52 & $\mathrm{~F}$ & fullness and discomfort & $20.5 \times 16$ & $\mathrm{~S}+\mathrm{CT}$ & NM & 2 years \\
\hline 5 & 2013 & Cappellani [13] & 67 & M & abdominal pain & $37 \times 24 \times 13$ & $\mathrm{~S}+\mathrm{CT}$ & $5 / 50 \mathrm{HPF}$ & 4 years \\
\hline 6 & 2013 & Notani [14] & 58 & $\mathrm{~F}$ & abdominal distension & $22 \times 19 \times 20$ & $\mathrm{~S}+\mathrm{CT}$ & $5-10 / 50 \mathrm{HPF}$ & 1 year \\
\hline 7 & 2015 & Ionescu [15] & 66 & M & abdominal distension & $25 \times 20 \times 27$ & $\mathrm{~S}+\mathrm{CT}$ & $21 / 5 \mathrm{~mm}^{2}$ & NM \\
\hline 8 & 2015 & our case & 76 & M & abdominal distension & $23 \times 20 \times 13$ & $\mathrm{~S}+\mathrm{CT}$ & $7-8 / 50 \mathrm{HPF}$ & 18 months \\
\hline
\end{tabular}

